\title{
Optimal placement and estimation of DG capacity in distribution network's using genetic algorithm-based method
}

\author{
Ali Aref $^{1 *}$, Mohsen Davoudi ${ }^{2}$ and Majid Davoudi ${ }^{3}$ \\ ${ }^{1}$ Department of Electrical Engineering, Takestan Branch, Islamic Azad University, Takestan, Iran. \\ ${ }^{2}$ Department of Electrical Engineering, Imam Khomeini International University, Qazvin, Iran. \\ ${ }^{3}$ Department of Electrical Engineering, Takestan Branch, Islamic Azad University, Takestan, Iran. \\ ali.aref89@yahoo.com, ${ }^{2}$ Mohsen.davoudi@polimi.it, ${ }^{3}$ m.davoodi1@yahoo.com.
}

\begin{abstract}
Distributed Generation (DG) unlike centralized electrical generation aims to generate electrical energy on small scale as near as possible to the load centers, interchanging electric power with the network. Moreover, DGs influence distribution system parameters such as reliability, loss reduction and efficiency while they are highly dependent on their situation in the distribution network. This paper focuses on optimal placement and estimation of DG capacity for installation and takes more number of significant parameters into account compare to the previous studies which consider just a few parameters for their optimization algorithms. Some of the so-called cost parameters are loss reduction, voltage profile improvement, environmental effects, installation and exploitation and maintenance expenses and costs of load prediction of each bus. Using an optimal Genetic Algorithm, proposed a destination function has been optimized which includes all of the cost parameters. This method is also capable of changing the weights of each cost parameter in the destination function of the Genetic Algorithm and the matrix of coefficients in the DIGSILENT environment. The cost parameters are variables dependent on the status and position of each bus in the network, putting forth an optimal DG placement. The proposed method has been applied and simulated on a sample IEEE 13bus network. The obtained results show that any change in the weight of each parameter in the destination function of the Genetic Algorithm and in the matrix of coefficients leads to a meaningful change in the location and capacity of the prospective DG in the distribution network.
\end{abstract}

Keywords: Distributed Generation (DG), Distribution Network, Optimization, Genetic Algorithm.

\section{Introduction}

Distributed generation (DG) is defined as small generation units installed in distribution systems. It is predicted that DG would have a share of about $20 \%$ of new generating units being on lined (Moghadas-Tafreshi, 2005). DG applications are growing due to environmental and economic issues, technological improvements, and privatization of power systems. DG application, however, has positive and negative side effects for public industries and consumers (Fotuhi-Firuzabad \& Rajabi-Ghahnavie, 2005; Farhadi et al., 2012). Generally, DG effects in distribution network depend on several factors such as the DG place, technology issues, capacity and the way it operates in the network. DG can significantly increase reliability, reduce losses and save energy while is cost effective, though it suffers from some disadvantages because of the isolated power quality functioning, and voltage control problems. Generally, planners assess DG functioning in two respects: costs and benefits. Cost is one of the most important factors that should be considered regarding DG application (Khattam \& Salama, 2004; Brown et al., 2001; Seyed Ali Mohammad Javadian \& Maryam Massaeli, 2011a,b,c; Navid Khalesi \& Seyed Ali Mohammad Javadian, 2011).

There are so many DG placement methods in hand though each of these methods only focuses on some parameters. The optimal DG placement defined by Barker \& Mello (2000) which includes reliability, loss reduction, and load prediction into account while it fails to account for other parameters such as productivity, cost effectiveness, and type of DG. The optimal DG placement is defined by Hadisaid et al. (1999) encompassing productivity, cost effectiveness, loss reduction, and reliability and DG type into account and fails to consider other parameters. Kashem and Ledwich (2002) focused on three parameters: DG cost, loss reduction and reliability. Also Dai and Baghzouz (2003) defined optimal DG placement method taking DG capacity, cost effectiveness and loss reduction into account. In addition, Girgis and Brahma (2001) defined optimal placement method taking stability, loss reduction and productivity into account. Robert and Market (2006) reported optimal DG placement method that takes loss reduction and load prediction into account. These fail to consider all aspects and parameters involving optimal DG placement. The present study is an attempt to define optimal DG placement by taking all pertinent parameters (loss reduction, voltage profile improvement, effects on environment, installation and exploitation and maintenance expenses and load prediction cost) into account and since DG type is selected based on DG location based on its installation capacity, parameters specific to the location must be determined.

Statement of the problem

Since the use of distributed sources is highly dependent on climatic and regional conditions, various
Research article

COIndian Society for Education and Environment (iSee)
"Genetic algorithm to estimate DG capacity" http://www.indjst.org
Ali Aref et al. Indian J.Sci.Technol. 
DG technologies have been developed. These technologies are divided into three general categories (Von-Jouanne et al., 2001; Teng et al., 2007): 1) Technologies working on fossil fuels such as combustion engines, micro turbines, and fuel batteries. 2) Technologies working on new sources of energy such as wind turbines, solar cells, wave energy, geothermal and biomass. 3) Technologies working on saving energy such as batteries, fly wheels, Superconducting Magnetic Energy Storage (SCMES), capacitors, Condensed Air Energy Storage (CAES) and Hydro pumps. Because of the traditional structure of power networks and lack of an active source of generation in the distribution system, as the installed capacity of generating sources increase, it becomes important to study the effects of these sources when they are working in tandem with electrical networks. The major effects of the distributed generation sources at the time of installment and exploitation include: 1) Voltage profile changes along the network based on production capacity of the units and based on consumption load. This can specially be observed in radial feeders. 2) Network losses change as a function of consumed load and production. 3) Transit currents and voltages appear in the network as the instant distributed generation sources connect or disconnect. 4) Quality of power and capability of the network protection system change. 5) Nowadays, because of the changes made in the power system structures for optimization purposes as well as the modernization of these structures, distributed generation sources are inevitably becomes important that in some countries they are considered as supplementary power supply systems. On the other hand, to satisfy the increasing power demand, huge power plants have to be constructed. There are, however, some obstacles such as finding a proper place for establishment, costs incurred due to the transfer of the electricity to places far away from the power plants, and the long interval between decision-making and actual exploitation. Hence, distributed generation is now of great importance to development planners because they can be connected to the network easily and close to the load. Distributed generation is obviously a new attraction for power industry, commercial and regulating systems (Singh \& Goswami, 2010).

In examining and identifying the technologies of DG sources and their effects on the distribution network, the technology being applied must be capable of producing the required power in order to enjoy the benefits of $D G$ sources in the distribution network. Also, optimal DG placement should be selected taking the conditions and status of each bus in the network (Huang \& Yang, 1996). The Proposed method

In the present study, for the above mentioned purpose, a destination function should be defined that includes all of the proposed parameters. The destination function, which is going to be minimized in this study and includes loss, voltage profile, environmental costs, installation and exploitation and maintenance expenses and cost of load prediction for each bus, is as follows:

$\left[F(x)=K_{1} \cdot C_{\text {Loss }}+K_{2} \cdot C_{V P I}+K_{3} \cdot C_{A}+K_{4} \cdot C_{D G}+K_{5} \cdot C_{L}\right](\$ / K W)$

where $C_{\text {LOSS }}$ is the cost of loss in all lines, $C_{V P I}$ is the cost voltage profile improvement, $C_{A}$ is the cost incurred due to effects on environment, $C_{D G}$ is the cost of installation, exploitation and maintenance and $C_{\mathrm{L}}$ is the cost of load prediction for each bus and for the buses in which the load amount is not predictable. DGs must save energy and this requirement incurs costs which have been taken into account in the above function. To define the destination function in (1), we have to make all parameters per unit to make them additive, this was accomplished by applying " $K$ " coefficients $\left(K_{1}-K_{5}\right)$. To calculate the cost of loss, first load flow is carried out in DIGSILENT software and then the results are used to calculate the losses and ultimately they are multiplied by the loss price. To calculate the cost of voltage profile improvement for each bus, the voltage difference for each bus is calculated before and after DG installment and the difference figure is multiplied by the cost of voltage profile improvement. To calculate pollution reduction cost using DG sources, the present study takes into account the variability of these coefficients for each bus depending on the type of the DG technology, and the cost incurred due to pollution which is calculated (Kaplan, 1984).

DG cost includes primary cost and exploitation and maintenance costs, which is defined as follows (Teng et al., 2007):

$$
C_{\mathrm{DG}}=a+b P(\$ / K W)
$$

Where $P$ is the nominal active power of DG. Also, $a$ and $b$ are calculated using the following formula:

$$
a=\frac{\text { Capital Cost }(\$ / K W) \times \operatorname{Capacity}(K W) \times G r}{\text { Life Time }(\text { Year }) \times 365 \times 24 \times L F}(\$ / K W)
$$

$b=$ Fuel Cost $(\$ / K W)+O \& M \operatorname{Cost}(\$ / K W)$

Where $G r$ is the annual rate of interest and $L F$ is the load coefficient of DG. In this study, these values are considered equal to unity. Each of the environmental coefficients affects on DG installation, exploitation, maintenance expenses and load prediction. All of the parameters have been defined in DIGSILENT in the form of a matrix that represent variables of each bus. Such values are shown in Tables 1-12. This paper has two major goals: 1) Improvement of voltage profile, 2) Loss reduction. There are also some limitations based on which the destination function should be defined (Baghzouz, 2005):

1. (Loss with $D G)<($ Loss without $D G)$

2. $V_{b u s}^{\min } \leq V_{b u s} \leq V_{b u s}^{\max }$ 
According to the first limitation the loss reduces when DG exists. Also, second limitation states that the authorized voltage of a certain bus depends on the minimum and maximum voltages of the bus.

\section{Simulation network}

Table 1. Data on the lines

\begin{tabular}{|c|c|c|c|}
\hline Sen.bus & Res.bus & $\mathrm{R}(\mathrm{ohm})$ & $\mathrm{X}(\mathrm{ohm})$ \\
\hline 1 & 2 & 0.176 & 0.138 \\
\hline 2 & 3 & 0.176 & 0.138 \\
\hline 3 & 4 & 0.045 & 0.035 \\
\hline 4 & 5 & 0.089 & 0.069 \\
\hline 5 & 6 & 0.045 & 0.035 \\
\hline 5 & 7 & 0.116 & 0.091 \\
\hline 7 & 8 & 0.073 & 0.073 \\
\hline 8 & 9 & 0.074 & 0.058 \\
\hline 8 & 10 & 0.093 & 0.093 \\
\hline 7 & 11 & 0.063 & 0.050 \\
\hline 11 & 12 & 0.068 & 0.053 \\
\hline 7 & 13 & 0.062 & 0.053 \\
\hline
\end{tabular}

In the proposed work, in order to observe and compare the results with those of the specified destination function, an IEEE 13-bus distribution network has been selected as a sample. It should be noted that the specified destination function can be generalized to be used for all distribution networks with any number of buses. Moreover, the optimization algorithm of the destination function is a Genetic Algorithm whose chromosomes are as analogous to the variables of location and capacity of DG. The single line diagram of the network is illustrated in Fig. 1. According to Fig. 1, 13-bus network contains two feeding sources in buses 1 and 6. Tables 1 and Table 2 show the data on the lines and buses (Chiang \& Wang, 1995).

Fig. 1. Single line diagram for IEEE 13-bus distribution network

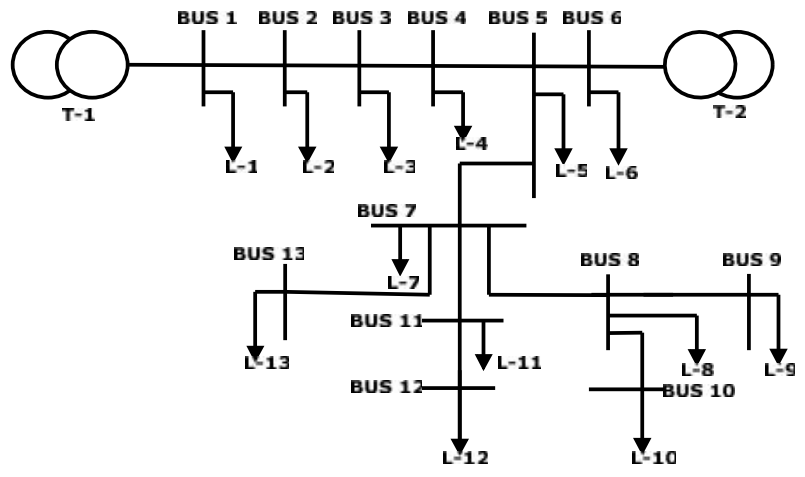

\section{Simulation}

This study aims to optimize the placement of DG and assess DG capacity using weight coefficients for various parameters independently taking cost into account. The coefficients of the first case shown in Table 3 include loss-reduction parameters like voltage profiles, environmental factors, installation and exploitation and maintenance expenses and load prediction in the destination function of the Genetic Algorithm shown by
Vol. 5 No. 3 (Mar 2012)

ISSN: 0974- 6846
Table 3. Coefficients applied to the parameters under the first (1) condition

Table 2. Data on the buses

\begin{tabular}{|c|c|c|}
\hline No.bus & $\mathrm{P}(\mathrm{kW})$ & $\mathrm{Q}(\mathrm{kVAR})$ \\
\hline 1 & 0 & 0 \\
\hline 2 & 890 & 468 \\
\hline 3 & 628 & 470 \\
\hline 4 & 1112 & 764 \\
\hline 5 & 636 & 378 \\
\hline 6 & 474 & 344 \\
\hline 7 & 1342 & 1078 \\
\hline 8 & 920 & 292 \\
\hline 9 & 766 & 498 \\
\hline 10 & 662 & 480 \\
\hline 11 & 690 & 186 \\
\hline 12 & 1292 & 554 \\
\hline 13 & 1124 & 480 \\
\hline$\left(k_{1}-k_{5}\right)$ in the destination function. However, other
\end{tabular}

coefficients shown in Table 4 are related to the weight of parameters for the effects of environmental factors, installation and exploitation and maintenance expenses and load prediction which are defined in an input matrix for the simulation software. In this case, since parameters related to loss reduction and voltage profile are calculated automatically, the coefficients of these parameters are not considered in the input matrix for the software. Thus, generally, parameters for any network have two conditions of weight coefficients with any number of buses. This has been achieved using genetic algorithm optimization in DIGSILENT environment.

The parameter changes are illustrated because they are variable in each bus. Optimization is carried out with Genetic Algorithm using a cost function. For this purpose, changes in the coefficients of the parameters are specified due to their variability in each bus. Optimization of the destination function has been carried out using a Genetic Algorithm.

\begin{tabular}{|c|l|c|}
\hline Coefficient & \multicolumn{1}{|c|}{ Parameter } & $\begin{array}{c}\text { Coefficients applied to each } \\
\text { parameter in destination } \\
\text { function }\end{array}$ \\
\hline$K_{1}$ & Loss reduction & $30 \%$ \\
\hline$K_{2}$ & Voltage profile & $20 \%$ \\
\hline$K_{3}$ & Effects on environment & $15 \%$ \\
\hline$K_{4}$ & DG cost & $15 \%$ \\
\hline$K_{5}$ & Load prediction cost & $20 \%$ \\
\hline \multicolumn{2}{|c|}{ To assess the effect of loss reduction, voltage profile }
\end{tabular}
coefficient, environmental coefficient, installation and exploitation and maintenance expenses and load prediction cost on the program, the program output was examined under two conditions (1), (2). For this purpose, different coefficients were applied to destination function parameters. Table 3 presents coefficients applied to parameters under the first condition, where parameters may vary depending on the place of the bus.

In addition, Table 4 presents an example of the weight of each parameter such as environmental pollution,
Research article

COIndian Society for Education and Environment (iSee)
"Genetic algorithm to estimate DG capacity" http://www.indjst.org
Ali Aref et al. Indian J.Sci.Technol. 
Table 4. An example of the weights of each parameter

\begin{tabular}{|c|c|c|c|}
\hline Bus No & $\begin{array}{c}\text { Coefficients } \\
\text { applied in each } \\
\text { bus to effect on } \\
\text { environment }\end{array}$ & $\begin{array}{c}\text { Coefficients } \\
\text { applied in each } \\
\text { bus to DG cost }\end{array}$ & $\begin{array}{c}\text { Coefficients } \\
\text { applied in each } \\
\text { bus to load } \\
\text { prediction cost }\end{array}$ \\
\hline 1 & $10 \%$ & $10 \%$ & $5 \%$ \\
\hline 2 & $5 \%$ & $10 \%$ & $10 \%$ \\
\hline 3 & $5 \%$ & $5 \%$ & $10 \%$ \\
\hline 4 & $10 \%$ & $20 \%$ & $5 \%$ \\
\hline 5 & $5 \%$ & $10 \%$ & $10 \%$ \\
\hline 6 & $10 \%$ & $5 \%$ & $5 \%$ \\
\hline 7 & $10 \%$ & $10 \%$ & $5 \%$ \\
\hline 8 & $5 \%$ & $10 \%$ & $25 \%$ \\
\hline 9 & $5 \%$ & $5 \%$ & $10 \%$ \\
\hline 10 & $10 \%$ & $10 \%$ & $5 \%$ \\
\hline 11 & $25 \%$ & $5 \%$ & $10 \%$ \\
\hline
\end{tabular}

installation and exploitation and maintenance expenses and load prediction under the first condition. Table 5 presents program outputs regarding to the optimal capacity and placement of the prospective DG.

Table 5. The program outputs

\begin{tabular}{|c|c|c|}
\hline DG NAME & LOCATION & KW \\
\hline Dg & BUS 9 & 1000 \\
\hline LOSS & LOSS & \\
Before & After & LII \\
DG & DG & \\
\hline 0.131266 & 0.128474 & 0.975628 \\
\hline VPI & VPI & VPII \\
Without & With & \\
DG & DG & 1.125554 \\
\hline 0.076923 & 0.086581 & \\
\hline
\end{tabular}

\section{Simulation Result}

Table 6. An example of the weights of each parameter

\begin{tabular}{|c|c|c|c|}
\hline Bus No & $\begin{array}{c}\text { Coefficients } \\
\text { applied in each } \\
\text { bus to effect on } \\
\text { environment }\end{array}$ & $\begin{array}{c}\text { Coefficients } \\
\text { applied in } \\
\text { each bus to } \\
\text { DG cost }\end{array}$ & $\begin{array}{c}\text { Coefficients } \\
\text { applied in each } \\
\text { bus to load } \\
\text { prediction cost }\end{array}$ \\
\hline 1 & $10 \%$ & $5 \%$ & $10 \%$ \\
\hline 2 & $5 \%$ & $10 \%$ & $10 \%$ \\
\hline 3 & $10 \%$ & $10 \%$ & $5 \%$ \\
\hline 4 & $10 \%$ & $5 \%$ & $20 \%$ \\
\hline 5 & $5 \%$ & $10 \%$ & $10 \%$ \\
\hline 6 & $25 \%$ & $5 \%$ & $5 \%$ \\
\hline 7 & $10 \%$ & $5 \%$ & $10 \%$ \\
\hline 8 & $5 \%$ & $25 \%$ & $10 \%$ \\
\hline 9 & $5 \%$ & $10 \%$ & $5 \%$ \\
\hline 10 & $5 \%$ & $5 \%$ & $10 \%$ \\
\hline 11 & $10 \%$ & $10 \%$ & $5 \%$ \\
\hline 1 & $p$ & $5 \%$ & \\
\hline
\end{tabular}

The proposed method has been developed in

DIGSILEN and MATLAB environments. The optimization algorithm in the present study is a Genetic Algorithm included in MATLAB, version 7 or higher applicable directly. Table 5 presents the candidate position for DG installation in a 13-bus network as well as the capacity of optimal DG in terms of (KW) using LII and VPII indexes.
Vol. 5 No. 3 (Mar 2012)

ISSN: 0974- 6846
Table 7. The program outputs

\begin{tabular}{|c|c|c|}
\hline DG NAME & LOCATION & KW \\
\hline dg & BUS 7 & 1060 \\
\hline $\begin{array}{c}\text { LOST } \\
\text { Before DG }\end{array}$ & $\begin{array}{c}\text { LOST } \\
\text { After DG }\end{array}$ & LII \\
\hline 0.131266 & 0.115848 & 0.882546 \\
\hline VPI Without DG & $\begin{array}{c}\text { VPI } \\
\text { With DG }\end{array}$ & VPII \\
\hline 0.076923 & 0.143230 & 1.862017 \\
\hline
\end{tabular}

Also, in the above outlet, line loss reduction index is defined by (Kim, 2001; Jouanne et al., 2001):

$$
L I I=\frac{L L_{W D G}}{L L_{W O D G}}
$$

Where $L L_{W D G}$ and $L L_{W O D G}$ are the losses incurred with and without $D G$ presence, respectively. This indicator can have the following implications under the three conditions: LII $<1$ : DG reduces loss, $L I I=1: D G$ is not

Table 8. Coefficients applied to the parameters under the second (2) condition

\begin{tabular}{|c|l|c|}
\hline \multirow{2}{*}{ Coefficient } & Parameter & $\begin{array}{c}|c| \\
\text { Coefficient applied to } \\
\text { each parameter in } \\
\text { destination function }\end{array}$ \\
\hline$K_{1}$ & Loss reduction & $40 \%$ \\
\hline$K_{2}$ & Voltage profile & $20 \%$ \\
\hline$K_{3}$ & $\begin{array}{l}\text { Effects on } \\
\text { environment }\end{array}$ & $10 \%$ \\
\hline$K_{4}$ & DG cost & $10 \%$ \\
\hline$K_{5}$ & Load prediction cost & $20 \%$ \\
\hline
\end{tabular}

effective and LII>1: DG increases loss.

Furthermore in Table 5, VPII indicates voltage profile improvement and shows the effect of DG placement on the voltage profile which is defined as follows (Huang et al., 1996; Kaplan, 1984):

$V P I I=\frac{V P_{W D G}}{V P_{W O D G}}$

Where $V P_{W D G}$ and $V P_{W O D G}$ are the voltage profiles with and without DG presence, respectively, and can be interpreted under the conditions such as: VPII<1: DG has a negative effect on network voltage, $V P \|=1: D G$ is not effective and VPII>1: DG has a positive effect on network voltage.

To observe the effect of each parameter including environmental pollution, installation and exploitation and maintenance expenses and load prediction cost, we changed the coefficients applied to each parameter in each bus in the form of a matrix. Table 6 presents the weight of another example of parameters such as environmental pollution, installation and exploitation and maintenance expenses and load prediction, under condition of Table 3. In addition, Table 7 presents program outputs regarding to optimal capacity and placement of DG. 
Table 9. An example of the weights of each parameter

\begin{tabular}{|c|c|c|c|}
\hline Bus No & $\begin{array}{c}\text { Coefficients applied in } \\
\text { each bus to effect on } \\
\text { environment }\end{array}$ & $\begin{array}{c}\text { Coefficients applied in } \\
\text { each bus to DG cost }\end{array}$ & $\begin{array}{c}\text { Coefficients applied in } \\
\text { each bus to load } \\
\text { prediction cost }\end{array}$ \\
\hline 1 & $10 \%$ & $20 \%$ & $5 \%$ \\
\hline 2 & $5 \%$ & $10 \%$ & $5 \%$ \\
\hline 3 & $10 \%$ & $5 \%$ & $10 \%$ \\
\hline 4 & $20 \%$ & $5 \%$ & $5 \%$ \\
\hline 5 & $5 \%$ & $5 \%$ & $10 \%$ \\
\hline 6 & $5 \%$ & $20 \%$ & $10 \%$ \\
\hline 7 & $5 \%$ & $5 \%$ & $5 \%$ \\
\hline 8 & $10 \%$ & $5 \%$ & $10 \%$ \\
\hline 9 & $15 \%$ & $10 \%$ & $5 \%$ \\
\hline 10 & $10 \%$ & $5 \%$ & $15 \%$ \\
\hline 11 & $5 \%$ & $10 \%$ & $20 \%$ \\
\hline
\end{tabular}

To test the program results under a different condition, we change all coefficients applied to the parameters of the destination function. Table 8 presents coefficients applied to parameters under different condition of Table 3 . In addition, Table 9 presents the weight of parameters such as environmental pollution, installation and exploitation and maintenance expenses and load prediction, under the same condition of Table 8. Also, Table 10 presents program output with regard to the optimal capacity and placement of DG.

Table 10. The program outputs

\begin{tabular}{|c|c|c|}
\hline DG name & Location & KW \\
\hline $\mathrm{dg}$ & BUS 9 & 1600 \\
\hline LOST & LOST & LII \\
Before & After & \\
DG & DG & 0.934101 \\
\hline 0.131266 & 0.122681 & \\
\hline VPI Without DG & VPI & VPII \\
& $\begin{array}{c}\text { With } \\
\text { DG }\end{array}$ \\
\hline 0.076923 & 0.080131 & 1.041704 \\
\hline
\end{tabular}

To observe the effect of each parameter including environmental pollution, installation and exploitation and maintenance expenses and load prediction cost, we changed again the coefficients applied to each parameter

Table 11. An example of the weights of each parameter

\begin{tabular}{|c|c|c|c|}
\hline Bus No & $\begin{array}{c}\text { Coefficients applied in } \\
\text { each bus to effect on } \\
\text { environment }\end{array}$ & $\begin{array}{c}\text { Coefficients } \\
\text { applied in each } \\
\text { bus to DG cost }\end{array}$ & $\begin{array}{c}\text { Coefficients applied in } \\
\text { each bus to load } \\
\text { prediction cost }\end{array}$ \\
\hline 1 & $5 \%$ & $20 \%$ & $5 \%$ \\
\hline 2 & $5 \%$ & $10 \%$ & $20 \%$ \\
\hline 3 & $10 \%$ & $5 \%$ & $5 \%$ \\
\hline 4 & $5 \%$ & $5 \%$ & $5 \%$ \\
\hline 5 & $10 \%$ & $5 \%$ & $10 \%$ \\
\hline 7 & $10 \%$ & $20 \%$ & $5 \%$ \\
\hline 8 & $5 \%$ & $5 \%$ & $20 \%$ \\
\hline 9 & $10 \%$ & $10 \%$ & $5 \%$ \\
\hline 10 & $5 \%$ & $5 \%$ & $5 \%$ \\
\hline 11 & $15 \%$ & $10 \%$ & $5 \%$ \\
\hline
\end{tabular}

Vol. 5 No. 3 (Mar 2012)

ISSN: 0974- 6846

in each bus. Table 11 presents the weight of another example of parameters such as environmental pollution, installation and exploitation and maintenance expenses and load prediction under the same conditions of Table 8. Finally, Table 12 presents program outputs with regard to the optimal capacity and placement of DG.

\section{Conclusions}

In this paper, we studied the effects of the significant parameters (such as reliability, loss reduction and efficiency) to optimally enhance the as loss reduction, voltage profile environmental effects, installation and exploitation and maintenance expenses and costs of predicting load of each bus). The cost parameters are

Table 12. The program outputs

\begin{tabular}{|c|c|c|}
\hline DG Name & Location & KW \\
\hline $\mathrm{dg}$ & BUS 7 & 1280 \\
\hline $\begin{array}{c}\text { LOST } \\
\text { Before DG }\end{array}$ & $\begin{array}{c}\text { LOST } \\
\text { After DG }\end{array}$ & LII \\
\hline 0.131266 & 0.112448 & 0.856643 \\
\hline VPI Without DG & $\begin{array}{c}\text { VPI } \\
\text { With DG }\end{array}$ & VPII \\
\hline 0.076923 & 0.085982 & 1.119594 \\
\hline
\end{tabular}

variables that depend on the status and position of each bus of the power network. Unlike the previous works on intelligent DG placement which all consider just a few parameters to be optimized; the proposed method uses all possible significant parameters into account to be formulized and optimized. A Genetic Algorithm based method has been developed in the DIGSILENT environment to apply to a sample IEEE 13-bus network to show the cost parameter optimization. It has been shown that any changes made in the weight of parameters such as loss reduction, voltage profile coefficient, coefficient of environmental pollution, installation and exploitation and maintenance expenses and load prediction cost in the destination function of Genetic Algorithm directly affect the optimal DG capacity and placement.

The final DG placement will be carried out with the purpose of improving voltage profile and loss reduction which cause the distributed generation capacity to be floating. In addition, it is concluded that the selection of distributed generation technology for specific and optimal placement purposes should be based on the types of the DG technology, while it should be conditionbased and purpose-based as well. 


\section{References}

1. Baghzouz Y (2005) Voltage regulation and overcurrent protection issues in distribution feeders with distribution generation - a case study. Proc. 38th Hawaii Int. Conf. on Sys. Sci. pp: 66-66.

2. Barker PP and de Mello RW (2000) Determining the impact of distributed generation on power systems. I. Radial distribution systems. Proc. IEEE Part-Radial Distribution System. 3, 1645-1656.

3. Brown RE, Jiuping $P$, Xiaornning $F$ and Koutlev $K$ (2001) Sitting distributed generation to defer T\&D expansion. Trans. \& Dist. Conf. \& Exposition. 2001 IEEE/PES. 2, 622-627.

4. Chiang HD and Wang JC (1995) Optimal capacitor placement replacement and Control in scale unbalanced systems. IEEE Tran. On Power apparatus \& Sys. 10, (1), 363-369.

5. Dai $C$ and Baghzouz Y (2003) On the voltage profile of distribution feeders with distributed generation. IEEE Power Eng. Society General Meeting. Vol 2. pp:

6. El-Khattam W and Salama MMA (2004) Distributed generation technologies, definitions and benefits. Elect. Power Sys. Res. 71, 119-128.

7. Farhadi $P$, Shayeghi $H$, Sojoudi $T$ and Karimi $M$ (2012) Customer reliability improvement and power loss reduction in distribution systems using distributed generations. Indian J.Sci.Technol. 5(3), This issue.

8. Fotuhi-Firuzabad M and Rajabi-Ghahnavie A (2005) An analytical method to consider DG impacts on distribution system reliability. IEEE/PES Dispt. \& Distribution Conf. \& Exhibition, Asia \& Pacefic. 9, 1-6.

9. Girgis A and Brahma S (2001) Effect of distributed generation on protective device coordination in distribution system. IEEE Conf. Large Eng. Sys. pp: 115-119.

10. Hadisaid N, Canard JF and Dumas F (1999) Dispersed generation impact on distribution networks. IEEE Com. Appl. Power. 12 (2), 22-28.

11. Huang YC and Yang HT (1996) Solving the capacitor placement problem in a radial system using Tabu search approach. IEEE Power \& Energy Soc. 11, 1868-1873.

12. Jouanne AV and Banergee B (2001) Assessment voltage unbalance. IEEE Trans. On Power Delivery. 16(4), 782-790.

13. Kaplan M (1984) Optimization of number, location, size, control type, and control setting of shunt capacitors on radial distribution feeders. IEEE Power \& Energy Soc. 103, 2659- 2665.

14. Kashem MA and Ledwich G (2002) Impact of distributed generation on protection of single wire earth return lines. Elect. Power Sys. Res. 62, (1), 6780.

15. Kim TE (2001) Voltage regulation coordination of distributed generation system in distribution systems.
Vol. 5 No. 3 (Mar 2012) ISSN: 0974- 6846

Proc.2004 IEEE IPES, Summering Meeting Vancouver. 1, pp: 480-484.

16. Moghadas-Tafreshi SM (2005) Electrical energy generation resources in $21^{\text {st }}$ century. K. N. Toosi University of Technol. Pres. 1st Edition. Tehran.

17. Navid Khalesi and Seyed Ali Mohammad Javadian (2011) Distribution system reliability with considering variation in DG and load consumption. Indian J.Sci. Technol. 4 (10), 1285-1289.

18. Robert A and Market (2006) Assessing voltage quality with relation to harmonics, flicker and unbalance. Proc. of IEEE Int. Conf.Simulation, Modeling \& Optimization. Lisbon, Portugal. pp: 112117.

19. Seyed Ali Mohammad Javadian and Maryam Massaeli (2011a) An adaptive overcurrent protection scheme for distribution networks including DG using distribution automation system and its implementation on a real distribution network. Indian J.Sci. Technol. 4 (11), 1438-1445.

20. Seyed Ali Mohammad Javadian and Maryam Massaeli (2011b) A fault location method in distribution networks including DG. Indian J.Sci. Technol. 4 (11), 1446-1451.

21. Seyed Ali Mohammad Javadian and Maryam Massaeli (2011c) Calculation of maximum DG's capacity according to their location for remaining the protection coordination in distribution networks. Indian J.Sci. Technol. 4 (11), 1452-1457.

22. Singh RK and Goswami SK (2010) Optimum allocation of distributed generations based on nodal pricing for profit, loss reduction, and voltage improvement including voltage rice issue. Int. J. Electrical Power \& Energy Sys. 32 (6), 637-644.

23. Teng JH, Liu YH, Chen CY and Chen CF (2007) Value-Based distributed generator placements for service quality improvements. Int. J. Elet. Power \& Energy Sys. 29, (3), 268-274.

24. Von-Jouanne A and Banergee B (2001) Assessment voltage unbalance. IEEE Trans. on Power Delivery. 16, (4), 782-790. 